\title{
INFORMATION SYSTEMS FOUNDATIONS - KARL POPPER'S THIRD WORLD
}

\author{
Craig McDonald \\ University of Canberra \\ craig.mcdonald@canberra.edu.au
}

\begin{abstract}
The various information professions have matured separately over the years, developing different bodies of theory and practice to meet their evolving purposes and needs. A problem arises however, when different information professions address the same knowledge domain and there is no explicit correspondence between the conceptual structures embedded independently in each. In this situation, a knowledge worker involved in the domain is faced with a range of possibly incompatible structures presented in different forms by a range of information professions. This is a common problem that is being exacerbated by the explosion in information production and the widening access to information distribution technology, notably the World Wide Web. Information Systems now need to combine the best of what the information professions in a domain have to offer the domain's knowledge workers. This paper examines the problem by exploring one of the foundations of the information disciplines - Karl Popper's 3 Worlds theory, applying it to a case study and suggesting that the Information Systems discipline alone has a sufficiently broad agenda to integrate the various Informatics themes needed to support today’s knowledge workers.
\end{abstract}

\section{POPPER'S THREE WORLDS}

The idea that the universe of human experience can be analysed in terms of three interacting worlds is an old one. Versions of the idea date back at least to Plato's cave analogy and to Aristotle ${ }^{8}$, but the elaboration by Karl Popper is an interesting contemporary formulation. In Popper's theory, reality is divided into three parts:

... first, the world of physical objects or of physical states; secondly the world of states of consciousness, or of mental states, or perhaps of behavioural dispositions to act; and thirdly, the world of objective contents of thought. (Popper, 1972, p.106).

Popper distinguished thought, in the sense of the content of statements, and thought, in the sense of thought processes, as belonging to two entirely different worlds:

If we call the world of 'things' - of physical objects - the first world, and the world of subjective experiences (such as thought processes) the second world, we may call the world of statements in themselves the third world. (Popper, 1976, pp.180-1).

The Three Worlds theory is diagrammatically represented in Figure 1.

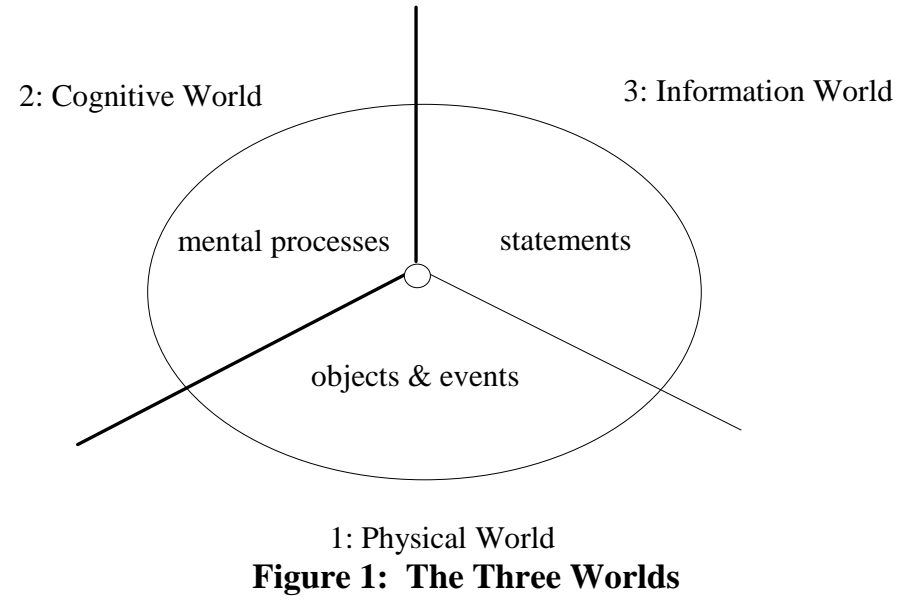

Turning first to the relationship between Worlds 1 and 2, consider a human, conscious mind (so in World 2) that perceives objects in the physical world (World 1). What it perceives is constrained first by the nature of the sense organs and lower brain functions, which exclude much potential stimulus, and, secondly, by the nervous system and brain which organise the stimulus that has been detected. Perception is the change of state in the mind as a result of paying attention to objects in World 1. Humans do not only perceive World 1, they also conceive it. That is, their sensing of the world is tempered and interpreted in terms of what they have learned and what they understand to be the significance of what they perceive. So when the mind in our scenario sees a full moon it is perceiving the light as a disc and conceiving of what the full moon might mean; perhaps romance, or danger.

8 All translations of classical works follow conventions for identifying paragraphs. The relevant references are Plato's Republic 514-516 and Aristotle's On Interpretation 16a4. 
There is, however, a two-way interaction between Worlds 1 and 2. The one described above is perception, the other is action. When the person makes a deliberate act, there is an effect on World 1 as a result of the World 2 state. Making a statement about the world is a special kind of human act. In its physical form, it is a part of World 1, speech sending out sound vibrations, for example. However, as a statement it is part of World 3. Statements are symbolic representations of concepts held by the speaker. These representations take the form of words and linguistic structures. Examples of objective knowledge are theories published in journals and books and stored in libraries; discussions of such theories; difficulties and problems pointed out in connection with such theories; and so on; “... we can call ... the world of the logical contents of books, libraries, computer memories, and suchlike 'World 3'”' (Popper 1972 pp.73-4).

World 2 acts on World 3 by writing, and inversely, by reading. Clearly words have physical properties and as such are in World 1. They are perceived through the senses, but what sets them worlds apart is that the concepts they evoke in the mind of the perceiver are not those of black marks on a page, or letters of the alphabet or words of the language, but what those words denote. A link in the mind is being made between the word, or symbol, and the World 1 reality to which it refers (shown by the dotted arrow). Figure 2 shows the interaction between the Three Worlds.

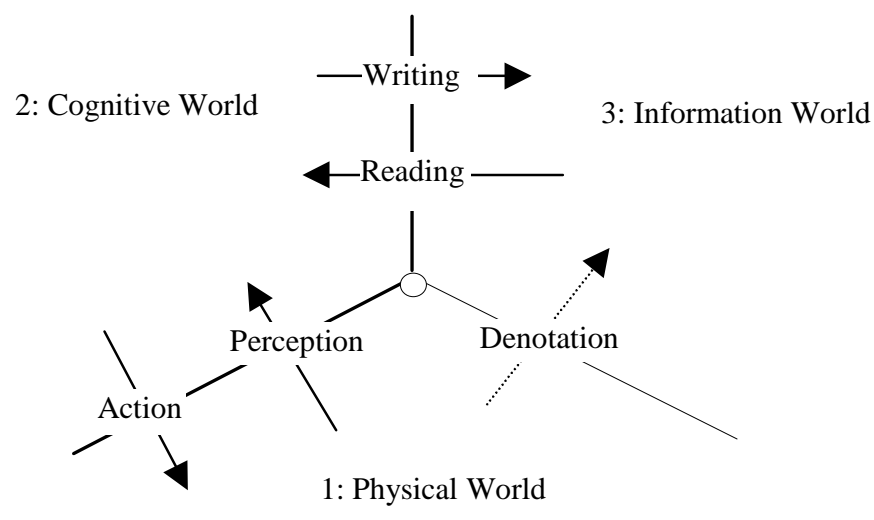

Figure 2: Interaction between the Three Worlds

The focus of this paper is on World 3, the information world, not with what it stands for in World 1, nor with who is creating and using it in World 2. This focus contrasts with research approaches such as sense making (Dervin, 1991) or discourse analysis (Beghtol, 1995; Olsson, 1998), which respectively take a cognitive or communicative approach in which the content of World 3 is largely incidental. The Three Worlds model isolates information from its human or physical context and allows it to be examined per se.

\section{POPPER AND COMMON THEMES IN INFORMATICS}

There are several major themes and terms that permeate the disciplines that study of World 3 . These themes are notoriously broad and are used to denote what are really many different ideas. Popper's ideas as described above provide the basis of an integrated Informatics theory within which the various themes can be comfortably accommodated.

\section{Information}

To Popper, a thought once "formulated in language so clearly that I can look at it critically from various sides ... is the thought in the objective sense". He continued "the decisive thing seems to me that we can put objective thoughts - that is, theories - before us in such a way that we can criticise them and argue about them. To do so, we must formulate them in some more or less permanent (especially linguistic) form” (Popper, 1976 p.182). The World 3 products of thought about the world take linguistic form; they are what this paper calls statements. This is not to say that all linguistic forms are in World 3; speech acts like greetings, curses or commands, for example, are not statements in Popper's sense.

Popper said that he peopled his World 3 with inmates including "statements or theories, also problems and arguments, especially critical arguments” (Popper, 1976 p.182). But he had earlier alluded to the idea that all abstractions are part of world 3 including "poetic thoughts and works of art” (Popper, 1972 p.106) and identified a wider class of inmates in World 3:

... we may regard the world of problems, theories and critical arguments as a special case, as a world 3 in the narrow sense, or the logical or intellectual province of world 3; and we may include in world 3 in a more 
general sense all the products of the human mind, such as tools, institutions, and works of art (Popper, 1976 p.187).

This wider scope for World 3 seems unavoidable in Popper's theory as, clearly, any abstraction that has been written down cannot be part of either World 1 or 2. However, Popper was a philosopher of science and his basic conception of World 3 seems to have been concerned with statements of a scientific kind. This paper is interested in Popper's special case of statements that are intellectual; statements of a scientific kind. Scientific statements may refer directly to World 1 , say as a theory or data about a physical phenomenon, or indirectly, as in a criticism of such a theory. As such criticism and argument themselves comprise statements, with their referents already in World 3, a statement may refer to either Worlds 1 or 3.

To Popper "the third world, the world of objective knowledge ... is man-made. But it is to be stressed that this world exists to a large extent autonomously; that it generates its own problems, especially those connected with methods of growth; and that its impact on any one of us, even on the most original of creative thinkers, vastly exceeds the impact which any of us can make upon it” (Popper, 1972, p 147). This autonomy and separation of World 3 from either the creator or user of objective knowledge is important because the idea of Information that is emerging is that it takes the form of statements that have been contributed to a domain of discourse and that refer either directly or indirectly to a set of World 1 phenomena. This definition of information is quite different from those that are based in the function of information. The Dictionary of Information Science and Technology, for example, defines information as the meaning assigned to data within some context for the use of that data (Watters 1992). To be operationalised, Watters' definition requires a particular cognitive context in order to tell if a particular statement is to be counted as information or not.

It is important to separate the structural and functional aspects of information because information systems are increasingly open - the characteristics and purposes of the knowledge workers they support are much less predictable than in the past.

\section{Concepts and Cognition}

Popper distinguishes between

... subjective knowledge (which should better be called organismic knowledge, since it consists of the dispositions of organisms) and objective knowledge, or knowledge in the objective sense, which consists of the logical content of our theories, conjectures, guesses...” (Popper, 1972 p.73)

Here he is drawing the distinction between tacit and explicit knowledge explained by Polanyi (1958). The term concept has been used to refer to a unit of knowledge and is reified in common usage to refer to units in both World 2 and World 3. The distinction is between one's having a concept (World 2) and there being a concept (World 3). The difference is that the first is a state of mind, of cognitive action, while the second is a statement. To Popper, meaning and understanding are World 2 processes. What a World 3 statement carries is the potential to create in its reader concepts similar to those held by its author. The statements do not mean anything on their own - meaning is an attribute of a single mind in action, not an attribute of a statement. This view has two implications. Firstly, given this idea, how can social groups display apparently collective, or shared, meaning (eg. "everyone understands what a red traffic light means")? The answer comes from the socialisation of people; the education, legal and law enforcement systems; and from other ways of aligning human behaviour, not from the proposition that a statement has 'objective' meaning. Secondly, the computer takes on a genuinely World 2 character as it takes a World 3 document (a computer program comprising statements) and executes them, generally producing new World 3 documents.

Information systems embody concepts. There is increasing need for systems to have World 3 schema that can be defined in a sharable way, just as language can define ideas in a sharable way between members of a society.

\section{Representation}

Popper saw World 2 being a mediator linking the two other worlds.

The three worlds are so related that the first two can interact, and the last two can interact. Thus the second world, the world of subjective or personal experiences, interacts with each of the other two worlds. The first world and the third world cannot interact, save through the intervention of the second world, the world of subjective or personal experiences (Popper, 1972 p.155).

Popper's description of World 2 as a mediator between Worlds 1 and 3 entails that a World 3 statement is a representation of a World 2 state. This raises the problem of the theory-ladenness of personal observation; all observers hold, in the subconscious, a myriad of preconceptions and biases about the way the world operates that affect their perception to make observations (Whitelaw et al, 1992). Semiology, Post-structuralism and Postmodernism have given very different accounts of the nature of language and the relationships between people, language and the world (Potter 1996). Understood from these accounts, language does not describe reality; it actually constitutes it (Cunningham \& Turner, 1993). 
Popper's principle of falsification provides a response to the issue. A statement, he argues, cannot be verified (i.e. proved to be true) but can be falsified by observing a counter example. In Conjectures and Refutations, Popper (1969) argues that to be admitted to World 3, a statement, as a conjecture, must be refutable; that is testable at some point against World 1, not just World 2. For information systems the issue of representation is core as systems embody concepts and data that needs to be valid and effective in their domains. Systems analysis is about the questioning and verification of concepts that systems hold and use.

\section{Communication}

It was Harold D. Laswell (1948) who seems to have first described a general model of communication identifying a flow of information involving a source, message, medium, receiver and effect. He suggested that this might be a useful way to structure communication research with separate research agendas for each component of the model - control studies, content analysis, media analysis, audience analysis and effect analysis.

This communication theme concentrates on either the production of a message or the change that a message engendered in a receiver. Because the focus of communication is on the expression of the sender's mental state or the mental state of the receiver rather than the message itself, it is a World 2-oriented approach. Popper included messages in World 3 several times in his writings (eg.Popper, 1982, p.115; 1972, p.157) but it seems that he thought of a message as having a more perennial nature than the modern day usage of the term. To Popper “.... books and journals can be regarded as typical World 3 objects” (Popper, 1976, p.182) rather than a telephone message or an e-mail message, but increasingly document management technology is redefining what it is that constitutes a 'document' and information systems are storing a variety of 'grey' information.

\section{Integrating Informatics Themes}

The informatics themes discussed above can be integrated in the Popperian framework shown in Figure 3. The subject of a document, the referent, is shown in Popper's World 1 or 3 . The generator and user of a document are in World 2, the world of states of consciousness, or of mental states. The documents containing statements make up World 3, the world of Poppers “objective contents of thought”. This theoretical framework accommodates all the informatics themes.

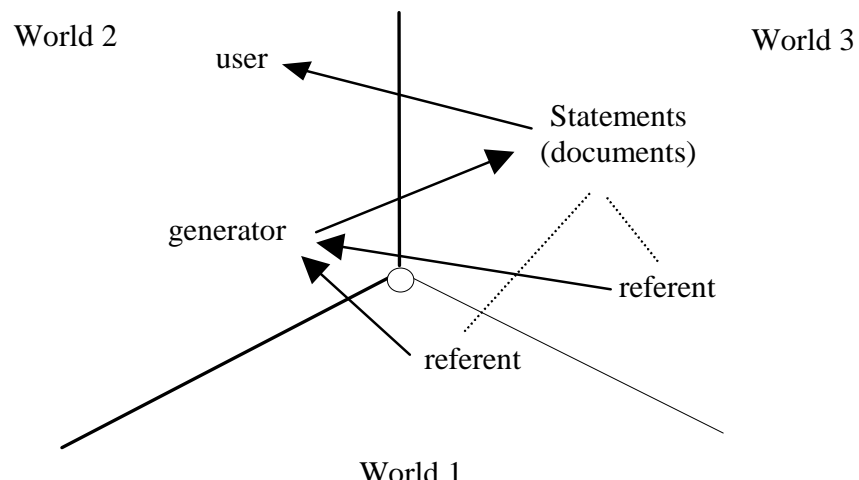

Figure 3: Integrated Informatics Themes in a Popperian Framework

Debates about epistemology, consciousness and the relationship between mind and the world have gone on for thousands of years. The advent of the computer has made some major changes to these debates as it can represent and process symbols, functions previously thought to be characteristics of mind not machine (Borgmann, 1999; Hobart \& Schiffman, 1998). In the face of these changes, Popper's views remain forceful as an Informatics theory.

The theoretical base presented above can now be used to develop an operational framework for knowledge domains and to integrate the various information professions that are active in domain analysis and formulation, and in the service of domain knowledge workers.

\section{KNOWLEDGE DOMAINS AND INFORMATION PROFESSIONS}

World 3 has been presented so far as a fairly amorphous collection of statements, but it is actually structured, complex and dynamic. This section gives some form and structure to the notion of World 3, showing that the body of information recorded about some phenomenon has an underlying ontological structure that this is presented in artefacts used by the information professions. 
Domain has been used to refer to very broad areas, for example, the 'domain of the Humanities', and to very small areas, as, for example, in Mathematics, where domain refers to the set of elements to which a mathematical or logical variable is limited and on which a function is defined. In the Information Systems discipline, an application domain is the specification of the objects, relationships and behaviours that exist within a particular system. Domain in this paper refers to the body of information that is recorded about some phenomena.

\section{Domain Scope}

Hirschfeld \& Gelman (1994) argue that while "some domains appear to carve the world at its joints" (p.25), the degree to which a domain is dependent on the world is complex and variable and that "a principled way of defining what a domain is continues to elude us" (p.25). Just as the common use of the term concept tends to confuse its World 2 and World 3 meanings, so a common sense use of domain tends to confuse its World 1 and World 3 meanings. As a World 1 idea, domain would refer to an interrelated set of phenomena. However, several different World 3 domains might address the same phenomena. A child's behaviour, for example, can be seen from the psychological, sociological, physical or educational viewpoints, each supported by a different body of World 3 theory and information. As a World 3 idea, domain is simply a set or cluster of interrelated statements.

However, the above definition does not give any way of isolating one domain from others in World 3 . World 3 is a passive place, a store of statements. The statement of what constitutes a domain is just like any other statement in World 3. A domain is a concept like any other, created in World 2 and reported explicitly in World 3. For example, a document describing the concepts in a university course in Plate Tectonics isolates the domain of Plate Tectonics, at least as seen by the professor who authored it. Other documents from other sources that seek to give an account of Plate Tectonics may well see the domain differently.

\section{Forms of Domain Content}

The physical nature of documents used to hold information is largely text-based, traditionally on paper in books and journals, more frequently now in full text electronic form and in hypertext. There are other, less obvious, documents that hold World 3 statements. A knowledge-based computer system, for example, comprises statements in a formal logic language, a computer simulation system comprises statements in mathematical language and a database system comprises statements in a data definition language. All these computing systems can be seen as documents holding statements in World 3. While all statements are information, the form of computer-based statements makes them a special kind of information. The terms data and knowledge are controversial in Informatics, but Popper's three worlds model allows a clear definition of them to be made.

Data is a kind of statement with a specific structure. It is a statement that identifies the value of an attribute of a phenomenon. For example the statement "the author of the book, Dilemmas in the Study of Information is S. D. Neill” is data because it identifies that a phenomenon (the particular book) has an attribute (the author), which has a value (his name). The components of data statements are parts of a domain theory, in this case a theory in which books and authors play some role. As data is symbolic it is in World 3 but it has a very close relationship to the World 1 phenomena it represents - the representation is concrete. Figure 4 shows the location of data statements in World 3. Information is generally contributed to World 3 via World 2, but data can be electronically or mechanically detected and recorded directly into World 3.

Knowledge has many definitions, most of which view it as a capacity or an ability of some agent to process information. As such, knowledge belongs in the cognitive world, not the information world. However, statements that represent knowledge are a different matter. They are statements that assert relationships between concepts that can be used in reasoning, once they have been learned or programmed into an informationprocessing agent (Debenham 1989). Represented knowledge is in World 3, but when it is activated, in a human mind or a computer, it is in World 2. Figure 4 shows the location of represented knowledge in World 3.

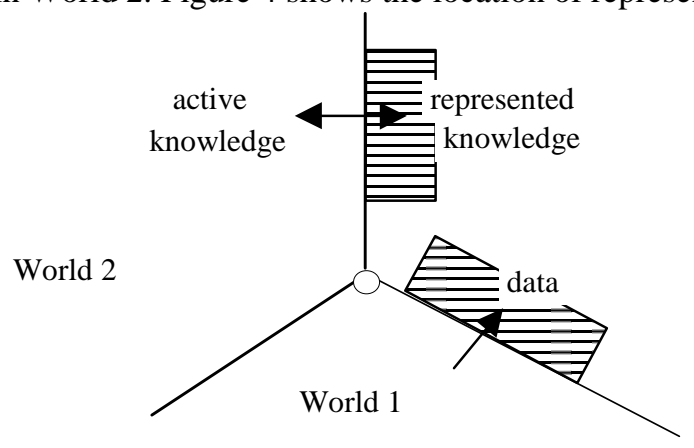

World 3

Figure 4: Data and Knowledge as special kinds of information in World 3 
World 3 then, comprises information in the form of statements. Two special kinds of statements are data and represented knowledge. Information systems accept and store information and make it available to World 2 agents - knowledge workers of the human and computer kinds. For such systems to be possible an ontology underlying World 3 is necessary.

\section{Ontology}

As a philosophical term, ontology concerns the branch of metaphysics that investigates the nature of being or existing (the other branch is cosmology, the theory describing the origin and structure of the universe). "If one asks whether there are numbers and other abstract objects, or whether there are properties, one is asking ontological questions” (Guttenplan, 1994, p.452). Koepsell (1999) argues that ontology is distinguished from meta-physics by being concerned with categories rather than with "being qua being ... Ontology may include such objects as angels, apples and Bosnia without addressing the typically metaphysical questions of whether angels exist or how many can fit on the head of a pin” (p.217). A distinction can be made between what might be called pure ontology, being qua being, and applied ontology, which concerns the exposing of the conceptual underpinning of a problem or position (Smith 1999).

The scope of an ontology is either global, attempting to organise and categorise everything that is possible in the universe (Aristotle; Ranganathan, 1967; Poli, 1996), or local to a domain (van der Vet \& Mars, 1998; Guber, 1993). Lehmann (1993) produced a draft 'concept systems catalogue' with more than two hundred ontological schemes in the collection.

Ontologies have numerous uses. Smith (1999), from a Computer Science perspective, identifies roles for an ontology in knowledge engineering, information retrieval and extraction, natural language translation, database design, conceptual modelling, information systems design and enterprise integration. Guarino (1998) says that its importance is being recognised in information modelling and object-oriented analysis, knowledge management and agent-based systems design. Vickery (1997), and Sowa (1984) describe how ontology is increasingly being used to refer to a class of artefacts that identify and describe the conceptual structure of a domain. Unfortunately, the information professions have over time selected and developed domain scopes, user typing, ontologies and ways of expressing ontologies in isolation from each other.

\section{The Information Professions}

The information professions are those groups of practitioners that take as their subject matter the organisation and mobilisation of information. Machlup \& Mansfield (1983) identified over thirty information professions. Each profession can be viewed as a particular kind of mediator between information in World 3 and a particular kind of user in World 2. For example, the Teaching profession might be primarily concerned with building cognitive ability in students, however in achieving this end it needs to organise the concepts in the domain being taught. The same domain may well be being organised quite separately by another profession, say Librarianship for its own reasons. The professions both have a defined and common set of phenomena to address - the information domain; it is in a common form - language; and they may well have a common clientele.

Each profession has created a range of methods and tools that it uses to specify the conceptual structure, the ontology, of the various knowledge domains that it addresses. Examples of these methods include the representation techniques for specifying data and knowledge structures in the Information Systems profession, the methods of cataloguing and classification of books in the Library profession, and curriculum and subject matter design in the Teaching profession. The context and aims of each profession have influenced the development of the methods and tools it uses.

\section{The Library Profession}

A library's "fundamental purpose is to acquire, organise, disseminate, or otherwise provide access to the vast bodies of knowledge already produced” (Rubin, 1998, p 171). There has been a shift of emphasis from the collection and storage of books that characterized the library of thirty years ago to the provision of access to information in physical or electronic forms today. The evolution of virtual or digital libraries (Vlib 2000) on the World Wide Web is increasingly providing a complement to the physical library.

The ontological artefacts that Library professionals use to describe and organise documents are a classification scheme and controlled vocabularies, including the thesauri and subject heading lists. Document descriptions are stored in catalogues that can be accessed through information retrieval systems using the descriptors. Information retrieval by keywords from a catalogue, full text database or the World Wide Web can be supported by additional artefacts such as dictionaries and encyclopaedias.

\section{The Information Systems Profession}

The Information Systems profession is essentially concerned with the development of computer-based data management systems in a corporate setting (Whitten et.al., 1989). The systems collect, store and process data at 
the operational, tactical and strategic levels of an organisation. The Information Systems (IS) professional is concerned with issues of corporate data analysis and with the design of systems using information technology and addressing the human and organisational aspects necessary to make a data management system function effectively. Specialisations have developed to address the data management problems of specific industries, such as health informatics (Hersch 1995), of particular types of data management problems, such as bibliographic data and of particular technologies, such as database management systems or systems development methodologies.

The Information Systems specifications are ontological artefacts produced by a systems analyst/designer after a conceptual analysis of the application domain. This analysis defines the information and data types, constraints and processing rules, or algorithms, necessary to manage domain data. Systems are constructed from the specification using information technology such as database management systems and computer programming languages. McDonald (1996) shows how the various IS ontological artefacts (ie. specifications in the form of diagrams, etc) can be expressed in a common coherent language - Sowa’s Conceptual Graphs.

Information systems are often concerned with data and processing policies that are private to an organisation. The exponential growth in information systems applications has created a need for inter-operation or integration of systems for efficiency and consistency. This trend has exposed a considerable problem because the conceptual structures of individual systems are proving to be incompatible when they are merged. This integration problem is an example of the wider problem being addressed in this paper - detecting differences in domain structures.

\section{The Teaching Profession}

While Teaching is concerned with building cognitive ability in students, it is an information profession in so far as it organises and presents domain information to its users.

There is a wide range of learning theories and educational concepts that underlie teaching and learning practice, but most modern theory is centered on cognitive psychology (that students' learning is changing their mental models) and constructivism, that proposes:

... learning is an active process in which learners construct new ideas or concepts based upon their current knowledge. The learner selects and transforms information, constructs hypotheses, and makes decisions, relying on a cognitive structure to do so. Cognitive structure (i.e. schema, mental models) provides meaning and organisation to experiences and allows the individual to 'go beyond the information given'. (OLTC 1996) Here, again, part of the information world is being organised into a domain to suit the needs of a particular user, the student. From a World 3 perspective, texts used by the educator comprise the domain. These texts include the materials the educator produces for teaching, such as lecture notes and study guides and the textbooks they prescribe and refer to. The ontological artefacts that are used to represent the organisation of the domain can be found in curriculum specifications and in the conceptual organisation of lecture notes, study guides and textbooks teachers prescribe and use.

\section{The View of a Domain by the Professions}

This section has reviewed knowledge domains and three information professions and the kinds of ontological artefacts that they employ. Figure 5 shows a hypothetical domain with a set of documents and artefacts being used by three professions. 


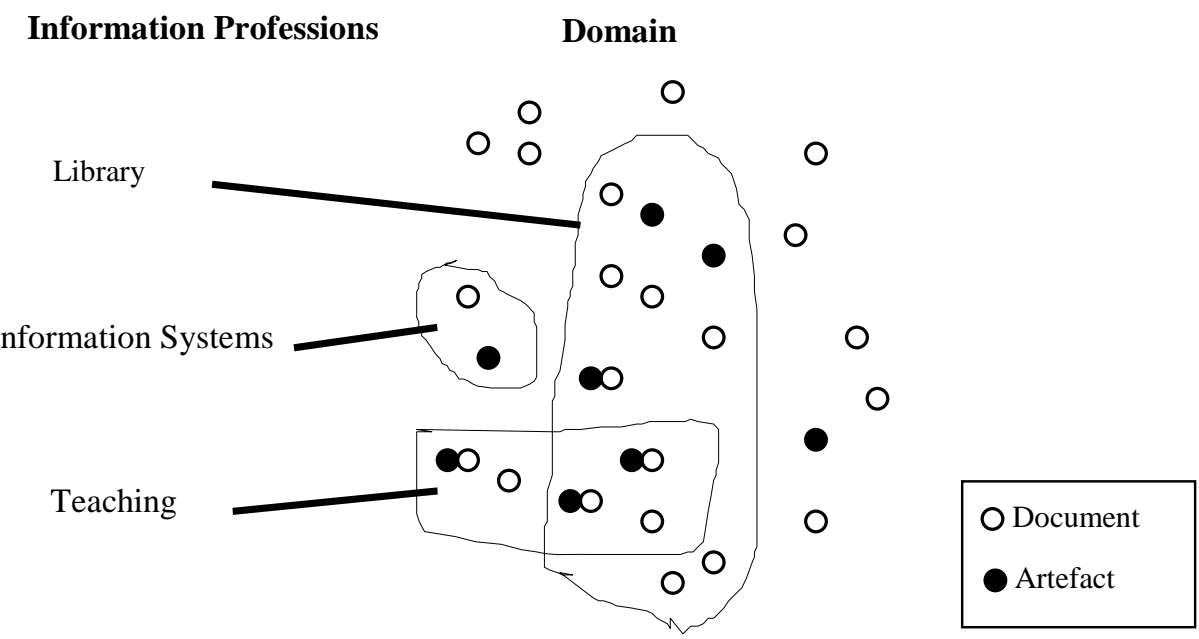

Figure 5: Information professions addressing different documents and artefacts in a domain

Some documents are not used at all, perhaps being inaccessible to all information professions in a particular local domain; some are shared by two professions - textbooks for example, that are part of the library collection and used in teaching; but generally documents are the preserve of one or other of the professions. Some artefacts are associated with a document, a back-of-the-book index for example; and others are not.

\section{A CASE STUDY}

The argument so far has separated out the main components of the information world and demonstrated the linkages between domain participants, documents, ontological artefacts, real-world phenomena, and information professions.

A problem arises however, when different information professions address the same knowledge domain and there is no explicit correspondence between the conceptual structures embedded independently in each. In this situation, a knowledge worker involved in the domain is faced with a range of possibly incompatible structures presented in different forms by a range of information professions. McDonald (2000) provides an example. The growing of grapes, Viticulture, is an ancient agricultural industry that has, during the twentieth century, increasingly become the focus of scientific research, mainly because of the value of the crop for wine making. There are specific research institutes for viticulture, the literature has been expanding rapidly and there are various courses in viticulture with different curricula. Figure 6 shows the relationships between the information professions, the user and the Viticultural domain at Charles Sturt University, Australia (CSU). The Viticulture domain comprises the collection of documents held by the academic library, the teachers' course notes and other teaching materials, and the specifications of a significant Viticultural information system (AusVit DSS). 


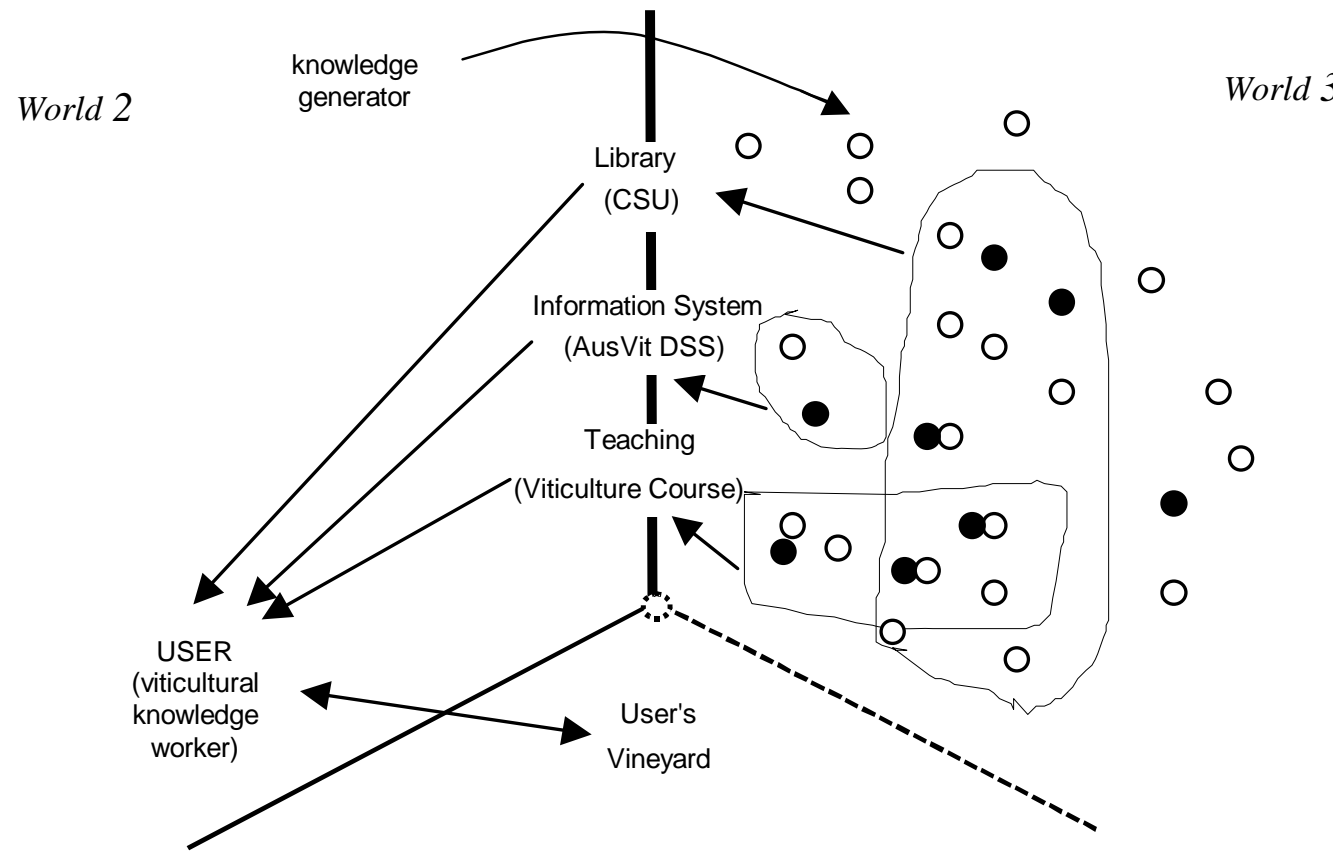

World 1

Figure 6: Full operational framework using the Viticulture domain at CSU as an example

A method for researching this situation, domain meta-analysis, was described by McDonald (2000). The method allows an analysis the concepts in domain organising artefacts and compares them to show the kinds of differences the professions have in their views of the structure of the Viticulture domain. Figure 7 is a Venn diagram showing the number of concepts contributed to the domain from each profession (Ip for the Librarianship profession, $\boldsymbol{t}$ for the Teaching profession and is for the Information Systems profession). The Teaching profession, for example, contributes 1730 concepts that are not used by either of the other professions, it shares 49 concepts only with the Librarianship profession, it shares 6 concepts with both the Librarianship and Information Systems professions and lastly it shares 44 concepts only with Information Systems.

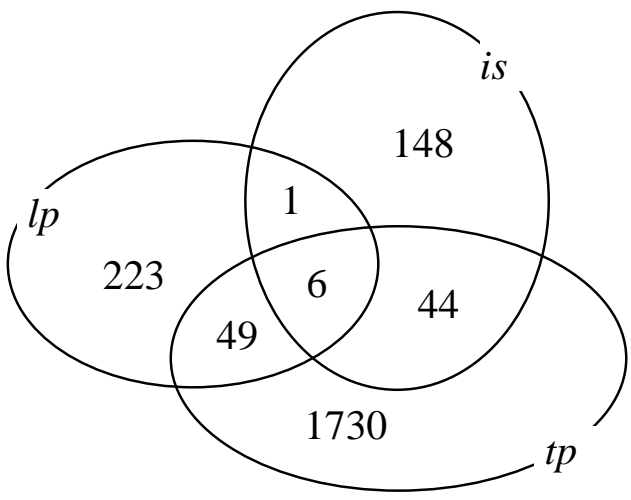

Figure 7: Venn diagram of the number of concepts by profession in the Viticulture domain (lp - Librarianship; tp - Teaching; is - Information Systems )

The total number of concepts in the Viticulture domain is 2201, the sum of the above segments. The numbers used here represent unique concepts. That is, a concept may be used many times in different professions but it is counted only once in the appropriate cell of the diagram. So acid-soil conditioners is unique to the Library profession and is one of the 223 concepts in that sector, australia occurs in both Librarianship and Teaching so is part of the 49 concepts shared by those professions, and diseases is used by all three professions so is part of the 6 in the central part of the diagram.

The problem for the user is that the different information professions address the same knowledge domain yet there is no explicit correspondence between the conceptual structures embedded independently in each. The user is faced with a range of possibly incompatible structures presented in different forms by a range of information professions. 


\section{CONSEQUENCES OF THE ARGUMENT}

A truly integrated Information System in Viticulture would address the above problem and, through a range of technologies, allow a knowledge worker to move seamlessly between the different conceptualisations of the Viticulture domain by the different information professions. As importantly, it would allow the professions to compare and discuss their conceptualisations. McDonald et al (1997) present a Knowledge Management System that would facilitate this kind of activity.

This paper has examined a problem faced by knowledge workers in a domain and at the same time exposed one of the foundations of Information Systems discipline - Karl Popper's 3 Worlds theory. There are other foundations - systems science, organisational behaviour, cognitive science and so on, but without a firm World 3 theory there is no way to integrate and systematise them.

The Information Systems profession is the one that is supposed to see the world systematically and holistically in terms of emergent properties, interacting parts, multiple views and so on, but it has restricted itself too much. That it has not moved much from its roots in the organisational data processing of thirty years ago has opened the door to new "fields" like BPR, eCommerce and Knowledge Management that are essentially just forms of Information Systems.

The Information Systems discipline is the only Informatics discipline that has the potential to accommodate the various forms of World 3, the technologies that store it and the knowledge workers who produce and use it. The future demands much more of the Information Systems discipline than it is currently delivering and if it does not start to produce Information Systems professionals with a much broader capacity, then some other discipline will arise that does.

\section{REFERENCES}

Beghtol, C. (1995) “Domain Analysis, Literary Warrant, and Consensus: The Case of Fiction Studies”, Journal of the American Society for Information Science 46(1), pp 30-44.

Borgmann, A. (1999) Holding On To Reality; The Nature of Information at the Turn of the Millenium, University of Chicago Press: Chicago.

Cunningham, S. \& Turner, S. (eds.) (1993) The Media in Australia Allen and Unwin: Sydney.

Debenham, J. (1989) Knowledge Systems Design, Prentice Hall: Englewood Cliffs, N.J.

Dervin, B. (1991) "Information as Non-sense; Information as sense: The Communication Technology Connection”, in Bouwman, H., Nelissen, P. \& Voojis, M. (eds.), Tussen vrag end Aanbod, pp 4-59.

Guarino, N. (1998) "Formal Ontology and Information Systems”

http://www.ladseb.pd.cnr.it/infor/Ontology/Papers/FOIS98.pdf

Guber, T. (1993) “A Translational Approach to Portable Ontologies”, Knowledge Acquisition, 5(2), pp 199229.

Guttenplan, S. (ed.) (1994) A Companion to the Philosophy of Mind, Blackwell: Oxford.

Hersh, W. R. (1995) Information Retrieval: A Health Care Perspective, Springer: New York.

Hirschfeld, L. A. \& Gelman, S. A. (1994) Mapping the Mind, Cambridge University Press: Cambridge.

Hobart, M. E. \& Schiffman, Z. S. (1998) Information Ages: Literacy, Numeracy and the Computer Revolution, The Johns Hopkins University Press: Baltimore.

Koepsell, David R. (1999) “Introduction to Applied Ontology: The Philosophical Analyses of Everyday Objects”, American Journal of Economics and Sociology 58(2), pp 217-220.

Lasswell, H. D. (1948). “The Structure and Function of Communication in Society”, in Bryson, L. (ed.) The Communication of Ideas, Harper and Row, pp 37-51.

Lehmann, F. (1993) http://briet.berkeley.edu/phil/categories.html

Machlup, F. \& Mansfield, U. (1983) The Study of Information: Interdisciplinary Messages Wiley: New York.

McDonald, C. (1996) “Information Systems Modelling and Conceptual Graphs”, Proceedings of $7^{\text {th }}$ Australian Conference on Information Systems, Hobart, December, pp 461-473.

McDonald, C., Pun, W. K. \& Weckert, J. (1997) “Knowledge Management for the Applied Sciences” Proceedings of the American Association for Artificial Intelligence Spring Symposium Series Artificial Intelligence in Knowledge Management, Stanford University, March, pp 110-114.

McDonald, C. (2000) Analysing and Coordinating the Conceptual Structures of the Information Professions (A Domain Oriented Approach), Unpublished PhD thesis, University of New South Wales.

Olsson, M. (1999) "Discourse: A New Theoretical Framework sor Examining Information Behaviour in its Social Context”, in Wilson, T. D. \& Allen, D. K. Exploring the Contexts of Information Behaviour, Taylor Graham, pp 136-149.

OLTC (1996) Open Learning Technology Corporation, http://www.oltc.edu.au/

Polanyi, M. (1958) Personal Knowledge, Routledge Paul: London.

Poli R. (1996) “Ontology for Knowledge Organisation”, in Green, R. (ed.), Knowledge Organization and Change, Indeks, Frankfurt, pp. 313-319 
Popper, K. R. (1969) Conjectures and Refutations: The Growth of Scientific Knowledge, $3^{\text {rd }}$ ed, Routledge Paul, London.

Popper, K. R. (1972) Objective Knowledge, An Evolutionary Approach Oxford, Clarendon Press, London. Popper, K. R. (1976) Unended Quest: An intellectual autobiography Fontana, London.

Potter, J. (1996) Representing Reality, Discourse, Rhetoric and Social Construction Sage, London.

Ranganathan, S. R. (1967) Prolegomena to Library Classification, $3^{\text {rd }}$ ed, Asia Publishing House, London. Rubin, R. E. (1998) Foundations of Library and Information Science, Neal-Schumann, New York.

Smith, B. (1999) “Ontology: Philosophical and Computational”,

http://wings.buffalo.edu/philosophy/faculty/smith/articles/ontologies.htm

Sowa, J. F. (1984) Conceptual Structures: Information Processing in Mind and Machine, Addison Wesley, Reading, MA.

van de Vet, P. E. \& Mars, N. J. I. (1999) “Condorcet Query Engine: A Query Engine for Coordinated Index

Terms”, Journal of the American Society for Information Science 50(6), pp 485-492.

Vickery, B .C. (1997) “Ontologies”, Journal of Information Science 23(4), pp 277-286.

Vlib (2000) http://vlib.org/AboutVL.html

Watters, C. (1992) Dictionary of Information Science and Technology, Academic Press, Boston.

Whitelaw, M., Weckert, J. \& McDonald, C. (1992) “Is Information Technology Shaping Human Cognition?”

Proceedings of ANZAAS Convention, Brisbane.

Whitten, J. L., Bentley, L. D. \& Barlow, V. M. (1989) Systems Analysis and Design Methods, $2^{\text {nd }}$ ed, Irwin, Homewood, IL. 